\title{
BUDAYA KESELAMATAN PASIEN DI RUMAH SAKIT DALAM MENINGKATKAN MUTU PELAYANAN DI RUMAH SAKIT
}

\author{
Intan Faadhilah
}

\author{
Intanfaadhilah24@gmail.com
}

\begin{abstract}
Abstrak
Penerapan budaya keselamatan pasien yang adekuat akan menghasilkan pelayanan keperawatan yang bermutu. Pelayanan kesehatan yang bermutu tidak cukup dinilai dari kelengkapan teknologi, sarana prasarana yang canggih dan petuugas kesehatan yang profesional, namun juga ditinjau dari proses dan hasil pelayanan yang diberikan. tujuan dari kajian ini adalah apabila pasien memiliki budaya yang berbeda dengan tenaga kerja kesehatan atau perawat agar melakukan komunikasi. Metode yang digunaka adalah metode kualitatif dimana maksudnya dengan cara mengumpulkan sebanyakbanyaknya data untuk dianalisis. Yaitu dengan Literature review ini dengan menganalisis yang berfokus pada budaya keselamatan pasien di rumah sakit dalam meningkatkan mutu pelayanan di rumah sakit. Adapun tinjauan literatur yang digunakan seperti buku teks, bukureferensi, jurnal, dan google scholar.Ada beberapa faktor yang menajdi penyebab kenapa budaya keselamatan pasien belum benar-benar diterapkan di berbagai rumah sakit.
\end{abstract}

KATA KUNCI :Budaya Keselamatan pasien, keselamatan pasien di rumah sakit, meningkatkan mutu pelayanan.

\section{Latar Belakang}

Penerapan budaya keselamatan pasien yang adekuat akan menghasilkan pelayanan keperawatan yang bermutu. Pelayanan kesehatan yang bermutu tidak cukup dinilai dari kelengkapan teknologi, sarana prasarana yang canggih dan petuugas kesehatan yang profesional, namun juga ditinjau dari proses dan hasil pelayanan yang diberikan (Ilyas, 2004).Budaya keselamatan pasien yang baik dapat memperkecil insiden yang berhubungan dengan keselamatan pasien.Penelitian Harvard School of Public Health (HSPH) (2011) menyebutkan bahwa dari seluruh dunia 43 juta orang dirugikan setiap tahun akibat perawatan yang tidak aman. Rumah sakit harus bisa memastikan penerima pelayanan Keselamatan pasien di rumah sakit (Hospital Patient Safety)merupakan suatu sistem pelayananrumah sakit yang memberikan asuhan agar pasien menjadi lebih aman. Termasuk didalamnya adalah mengukur risiko, identifikasi,dan pengelolaan risikoterhadap pasien, pelaporan, dan analisis insiden, kemampuan untuk belajar dan menindaklanjuti insiden serta merupakan solusi untuk mencegah, mengurangi, serta meminimalkan risiko. 


\section{TUJUAN}

tujuan dari kajian ini adalah apabila pasien memiliki budaya yang berbeda dengan tenaga kerja kesehatan atau perawat agar melakukan komunikasi .Contohnyapasien ada larangan tertentu dari budayanya yang bertentangan dengan tindakan medis yang akan di lakukan perawat terhadap pasien tersebut. Oleh karena itu perawat harus bertanya terlebuh dahulu kepada pasien itu agar tidak terjadi kesalah pahaman, atau pun sebelum perawat melakukan tindakannya harus meminta izin terlebih dulu kepada pasien tersebut ataupun keluarga pasien . Semua orang memiliki budaya yang berbeda-beda. Sebagai perawat juga harus memahami budaya pasien yang berbeda-beda, dan apabila pasien tersebut sudah mengizinkan kita melakukan tindakan yang akan di lakukan dan itu tidak melanggar budanya yang dianautnya maka perawat melakukan tindakannya tersebut. Jadi inti dari tujuan ini adalah harus berkomunikasi terhadap pasien agar tidak terjadi kesalahan atau pun tindakan yang tidak di harapkan.

\section{METODE}

Metode yang digunaka adalah metode kualitatif dimana maksudnya dengan cara mengumpulkan sebanyak-banyaknya data untuk dianalisis. Yaitu dengan Literature review ini dengan menganalisis yang berfokus pada budaya keselamatan pasien di rumah sakit dalam meningkatkan mutu pelayanan di rumah sakit. Adapun tinjauan literatur yang digunakan seperti buku teks, bukureferensi, jurnal, dan google scholar.Dengan kata kunciBudaya Keselamatan pasien, keselamatan pasien di rumah sakit, meningkatkan mutu pelayanan.Dan yang digunakan adalah 14 literatur yang diterbitkan 10 tahun terakhir.

\section{PEMBAHASAN}

Keselamatan pasien (patient safety) dapat diartikan sebagai upaya untuk mencegah suatu bahaya yang akan terjadi pada pasien. Konsep keselamatan pasien harus mampu dilaksanakan secara menyeluruh dan terpadu. Menurut The American Hospital Asosiation (AHA) 1999 keselamatan dan keamanan pasien ( patient safety), keutamaan strategik. Patient safety, sebuah sistem yang mampu memberikan rasa aman kepada pasien. Sistem pada Patient safety yang disebabkan oleh kesalahan dalam pengambilan tindakan dapat memperingankan cedera yang akan terjadi. Keselamatan pasien menurut Sunaryo (2009) adalah ada tidak adanya kesalahan atau bebas dari cidera karena kecelakaan.Patient safety mulai dicanangkan di Australia pada tahun 2000 oleh Ministry of Health (MOH) Australia.Di Indonesia sendiri dibentuk Komite Keselamatan Pasien Rumah Sakit (KKPR) pada tahun 2005 oleh Persatuan Rumah Sakit Indonesia (PERSI).Di Indonesia PERSI yang pertama kali membentuk dan menginisiasi Gerakan keselamatan pasien rumah sakit, yang diresmikan / dicanangkan oleh Menteri Kesehatan pada Pembukaan Seminar Nasional PERSI tanggal 21 Agusus 2005.Dugaan malpraktek yang dilakukan petugas pelayanan kesehatan yang mengakibatkan pasien mengalami kerugian mulai dari materi, cacat fisik bahkan sampai meninggal dunia memperlihatkan 
masih rendahnya mutu pelayanan kesehatan di rumah sakit.patient safety (keselamatan pasien) belum menjadi budaya yang harus diperhatikan oleh rumah sakit di Indonesia. Perubahan paradigma dalam lembaga pelayanan kesehatan yang saat ini beralih pada patient centered care belum benar-benar dijalankan dengan baik. Masih ada rumah sakit yang berorientasi pada kepentingann manajemen yang pada akhirnya melupakan keselamatan pasien di rumah sakit. Undangundang Kesehatan no 36 tahun 2009 sudah dengan jelas bahwa rumah sakit saat ini harus mengutamakan keselamatan pasien diatas kepentingan yang lain sehingga sudah seharusnya rumah sakit berkewajiban menerapkan budaya keselamatan pasien. Tidak ada lagi alasan bagi setiap rumah sakit untuk tidak menerapkan budaya keselamatan pasien karena bukan hanya kerugian secara materi yang didapat tetapi juga ancaman terhadap hilangnya nyawa pasien.Apabila masih ada rumah sakit yang mengabaikan keselamatan pasien sudah seharusnya diberi sanksi yang berat baik untuk rumah sakit maupun petugas pelayanan kesehatan.Beberapa kasus yang terjadi di Indonesia, pihak rumah sakit bahkan petugas pelayanan kesehatan tidak mendapat sanksi apapun sehingga menjadikan penegakan hukum kesehatan di Indonesia masih sangat lemah. Sudah seharusnya apabila terjadi kelalaian bahkan kesengajaan dari pihak rumah sakit yang mengakibatkan terancamnya keselamatan pasien maka tidak hanya sanksi internal tetapi juga sudah masuk ke ranah pidana. Inilah yang sampai saat ini belum berjalan sehingga masyarakat yang dirugikan karena lemahnya penegakan hukum yang pada akhirnya kasusnya menguap begitu saja. Ada beberapa faktor yang menajdi penyebab kenapa budaya keselamatan pasien belum benar-benar diterapkan di berbagai rumah sakit.Pertama, rendahnya tingkat kepedulian petugas kesehatan terhadap pasien, hal ini bisa dilihat dengan masih ditemukannya kejadian diskriminasi yang dialami oleh pasien terutama dari masyarakat yang tidak mampu.Kedua, beban kerja petugas kesehatan yang masih terlampaui berat terutama perawat. Perawatlah yang bertanggung jawab terkait asuhan keperawatan kepada pasien sedangkan disisi lain masih ada rumah sakit yang memiliki keterbatasan jumlah perawat yang menjadikan beban kerja mereka meningkat. Selain perawat, saat ini di Indonesia juga masih kekurangan dokter terutama dokter spesialis serta distribusi yang tidak merata. Ini berdampak pada mutu pelayanan yang tidak sama di setiap rumah sakit. ketiga, orientasi pragmatisme para petugas kesehatan yang saat ini masih melekat disebagian petugas kesehatan. Masih ditemukan para petugas kesehatan yang hanya berorientasi untuk mencari materi/keuntungan semata tanpa mempedulikan keselamatan pasien. Keempat, lemahnya pengawasan yang dilakukan oleh dinas kesehatan terhadap para petugas kesehatan. Lemahnya pengawasan sendiri dikarenakan beberapa faktor mulai dari terbatasnya personel yang dimiliki dinas kesehatan sampai rendahnya bargaining position dinas kesehatan. Keempat hal tersebut diatas yang setidaknya menjadi penghalang terwujudnya budaya keselamatan pasien di setiap rumah sakit.jika hal ini tidak segera diselesaikan maka kasus-kasus yang mengancam keselamatan pasien akan terus terjadi sehingga perlu upaya yang maksimal untuk mewujudkan budaya keselamatan pasien. Mulai diterapkannya aturan baru terkait akreditasi rumah sakit versi 2012 menjadi sebuah harapan baru agar budaya keselamatan pasien bisa diterapkan diseluruh rumah sakit di Indonesia.Selain itu, harus ada upaya untuk meningkatkan 
kesadaran para pemberi pelayanan kesehatan tentang pentingnya menerapkan budaya keselamatan pasien dalam setiap tindakan pelayanan kesehatan. Dan juga diperlukan sosialisasi yang masif kepada masyarakat terutama yang akan menggunakan jasa pelayanan kesehatan untuk meningkatkan pengetahuan serta memperbaiki perilaku mereka dalam memanfaatkan pelayanan kesehatan.

Upaya-upaya ini harus segera dilakukan agar tidak ada lagi kasu dugaan malpraktik yang dapat merugikan masyarakat sehingga mutu pelayanan kesehatan di rumah sakit bisa meningkat.Dengan meningkatkan kepedulian terhadap pasien maka dengan mudah budaya keselamatan pasien bisa dijalankan.Jangan sampai hanya karena kesalahan sedikit yang dilakukan oleh rumah sakit bisa berakibat pada rusaknya citra dunia perumah sakitan di Indonesia dimata internasional.

\section{PENUTUP}

Dalam penerapan program keselamatan pasien terdapat beberapa aspek yang mempengaruhi berjalannya program penerapan keselamatan pasien. Aspek-aspek tersebut antara Iain: iklim organisasi, tingkat pengetahuan, komunikasi, dan etika. Budaya keselamatan pasien akan tercipta apabila tenaga kesehatan memiliki pemimpin yang bersedia bekerja sama demi terlaksananya patient safety. Selain itu pengetahuan dan komunikasi juga berpengaruh terhadap ter:aksananya patient safety. Salah satu aspek yang penting dalam terlaksananya patient safety yaitu aspek etika. Etika sangatlah penting karena akan menyangkut tentang prosedur dalam melaksanakan asuhan keperawatan atau melaksanakan tugas dalam melayani kesehatan. Dalam pelayanan kesehatan maka tenag medis harus sesuai dengan kode etik dan hukum kesehatan.Hal ini untuk menghindari atau mengurangi praduga terjadinya malpraktik.

\section{REFERENSI}

Cahyono, A. (2015). Hubungan karakteristik dan tingkat pengetahuan Perawat terhadap pengelolaan keselamatan Pasien di rumah sakit. Jurnal Ilmiah WIDYA, 1(1), 97- 99.

Firawati. (2012). Pelaksanaan Program Keselamtan pasien di RSUD Solok. Jurnal Kesehatan Masyarakat. 6 (2), 74-77.

Harus, B., D., \& Sutriningsih, A. (2015). Pengetahuan Perawat Tentang Keselamatan Pasien dengan Pelaksanaan Prosedur Keselamatan Pasien Rumah Sakit (KPRS) di Rumah Sakit Panti Waluya Sawahan Malang. 3(1), 25-27.

Herawati, Y., T. (2015). Budaya Keselamatan Pasien di Ruang Rawat Inap Rumah Sakit X Kabupaten Jember. Jurnal Ikatan Kesehatan Masyarakat. 11(1), 54-58. 
Iskandar, E. (2017). Tata Kelola dan Kepatuhan Penerapan Standar Patient Safety Penyakit Stroke di Rumah Sakit Dr Kanujoso Djatiwibowo. Jurnal Administrasi Rumah Sakit. 3(3), 169-170.

Ismainar, H. (2019). Keselamatan Pasien di Rumah Sakit. Yogyakarta : Deepublish

Kemenkes RI. (2011). Permenkes RI No.1691/Menkes/VIII/2011 tentang Keselamatan Pasien Rumah Sakit.

Najihah. (2018). Budaya Keselamatan Pasien dan Insiden Keselamatan Pasien Di Rumah Sakit: Literature Review. Journal Of Islamic Nursing. 3 (1), 1-4.

Neri, R., A., Lestari, Y., \& Yetty, H. (2018). Analisis Sasaran Pelaksanaan Keselamatan Pasien di Rawat Inap Rumah Sakit Umum Daerah Padang Pariaman. Jurnal Kesehatan Andalas. 7 (4), $48-50$

Pagala, I., Shaluhiyah, Z., \& Widjasena, B. (2017). Perilaku Kepatuhan Perawat Melaksanakan SOP Terhadap Kejadian Keselamatan Pasien di Rumah Sakit X Kendari. Jurnal Promosi Kesehatan Indonesia, 12(1), 138-141.

Peraturan Menteri Kesehatan RI. (2011). Keselamatan pasien Rumah Sakit. Jakarta: Menteri Kesehatan.

Putri, S., Santoso, S., \&Rahayu, E. P. (2018).Pelaksanaan Keselamatan Pasien dan Kesehatan Kerja terhadap Kejadian Kecelakaan Kerja Perawat Rumah Sakit. Jurnal Endurance:

KajianIlmiahProblemaKesehatan, 3(2), 271-277

Qomariah, S. N., \& Lidiyah, U. A. (2015). Hubungan Faktor Komunikasi Dengan Insiden Keselamatan Pasien (Correlation of Communication Factor with Patient Safety Incident). Journals of Ners Community, 6(2), 166-170.

Rivai, F., Sidin, A., I., \& Kartika, I. (2016). Faktor Yang Berhubungan Dengan Implementasi Keselamatan Pasien Di Rsud Ajjappannge Soppeng Tahun 2015. Jurnal Kebijakan Kesehatan Indonesia. 5(4), 152-154.

Sakinah, S., dkk. (2017). Analisis Sasaran Keselamatan Pasien Dilihat dari Aspek Pelaksanaan Identifikasi Pasien dan Keamanan Obat di RS Kepresidenan RSPAD GatotSubroto Jakarta. Jurnal Kesehatan Masyarakat (e-journal), Vol 5, No4. Hal.145

Simamora, R. H. (2018). Buku Ajar Keselamatan Pasien Melalui Timbang Terima Pasien Berbasis Komunikasi Efektif: SBAR. 
Simamora, R.H. (2019). Buku Ajar : Pelaksanaan Identifikasi Pasien. Ponorogo, Jawa Timur: Uwais Inspirasi Indonesia.

Simamora , R. H. (2019). Documentation of Patient Identification into the Electronic System to Improve the Quality of Nursing Services . INTERNATIONAL JOURNAL OF SCIENTIFIC \& TECHNOLOGY RESEARCH , 1884-1886.

Simamora , R. H. (2019). Pengaruh Penyuluhan Identifikasi Pasien dengan Menggunakan Media Audiovisual terhadap Pengetahuan Pasien Rawat Inap . Jurnal Keperawatan Silampari Vol 3 No 1, 342-351.

Triwibowo, C., Yuliawati, S., \& Husna, N., A. (2016). Handover sebagai Upaya Peningkatan Keselamatan Pasien (Patient Safety) di Rumah Sakit. Jurnal Keperawatan Soedirman. Vol.11 (2). Hal $77-79$.

Wardhani, V. (2017). Buku Ajar Manajemen Keselamatan Pasien. Malang : UB Press.

Yasmi, Y., \& Thabrany, H. (2018). Faktor-Faktor yang Berhubungan dengan Budaya Keselamatan Pasien di Rumah Sakit Karya Bhakti Pratiwi Bogor Tahun 2015. Jurnal Administrasi Rumah Sakit. 4 (2), 99-103 